Check for updates

Cite this: Chem. Sci., 2019, 10, 6863

๑ All publication charges for this article have been paid for by the Royal Society of Chemistry

Received 14th May 2019

Accepted 7th June 2019

DOI: $10.1039 / \mathrm{c} 9 \mathrm{sc} 02341 \mathrm{k}$

rsc.li/chemical-science

\section{Hydroalkynylative cyclization of 1,6-enynes with terminal alkynes $\uparrow$}

\author{
Qi Teng, ${ }^{a}$ Nuligonda Thirupathi, ${ }^{a}$ Chen-Ho Tung (D) a and Zhenghu Xu (iD *ab \\ A rhodium-catalyzed highly regio- and enantioselective hydroalkynylation, generating cis- \\ hydrobenzofuranone-tethered enynes has been developed. The reaction proceeds with a selective \\ head-to-head insertion and symmetry breaking Michael addition cascade. One product was produced \\ from tens of possible isomers through precise control of chemo-, regio-, and stereoselectivities using \\ a single rhodium catalyst. Notable features of this method include $100 \%$ atom-economy, mild reaction \\ conditions and a very broad substrate scope.
}

\section{Introduction}

Conjugated enynes are a type of privileged structure distributed in a number of natural products ${ }^{1}$ and luminescent materials. ${ }^{2}$ They are also very important building blocks widely used in organic synthesis. ${ }^{3}$ The most attractive and atom-economic pathway to conjugated enynes is the transition-metal catalyzed direct addition of a terminal alkyne $\mathrm{C}-\mathrm{H}$ bond to a second alkyne moiety. ${ }^{4,5}$ Generally the acceptor alkynes are electrondeficient internal alkynes. ${ }^{4}$ Hydroalkynylation ${ }^{6}$ of a second terminal alkyne, also termed cross-dimerization of two different terminal alkynes is more challenging. This reaction could in principal produce six possible cross-dimerization products and six homodimerization side products (Scheme 1a). Ideally, the metal catalyst should selectively produce one isomer from 12 similar isomers, and consequently very few examples have been reported. ${ }^{5}$ Taking advantage of the steric and electronic differences of two alkynes, so controlling chemo- and regioselectivity is a possible solution. For instance, silyl alkynes were usually chosen to couple with aryl or aliphatic alkynes to give different products depending on the choice of catalyst. ${ }^{5 d, e}$ However, in all these reactions, undesired isomers were always produced together with the major product. ${ }^{5}$ Consequently, the development of a new synthetically useful strategy to realize selective cross-hydroalkynylation reactions to access conjugated enynes ${ }^{7}$ is important.

Generally, a metal acetylide complex was selectively formed, and subsequent syn insertion into the other triple bond usually

${ }^{a}$ Key Lab for Colloid and Interface Chemistry of Education Ministry, School of Chemistry and Chemical Engineering, Shandong University, Jinan 250100, People's Republic of China. E-mail: xuzh@sdu.edu.cn

${ }^{b}$ State Key Laboratory of Organometallic Chemistry Shanghai Institute of Organic Chemistry, Chinese Academy of Sciences, Shanghai 200032, PR China

$\dagger$ Electronic supplementary information (ESI) available: CCDC 1845186 for 3m and 1847564 for 3p. For ESI and crystallographic data in CIF or other electronic format see DOI: $10.1039 / \mathrm{c} 9 \mathrm{sc} 02341 \mathrm{k}$ led to two different alkenyl metal intermediates because both head-to-head and head-to-tail insertion are possible.

Completely selective formation of one intermediate over another similar intermediate is generally unlikely and most reactions reported always led to one major product together with other isomers as minor products. ${ }^{5}$ When aryl alkynes were reacted with propargyl alcohol, head-to-head dimers were obtained as a major product in the presence of a palladium

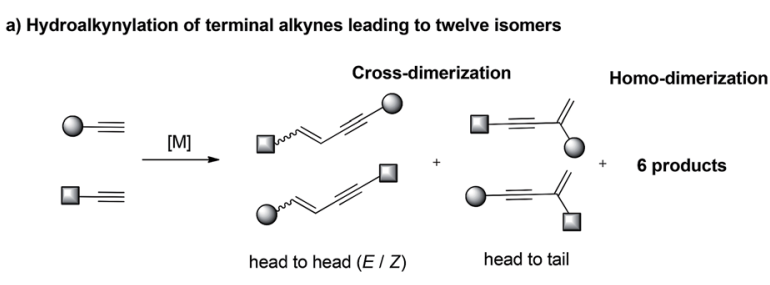

b) Rh-catalyzed head-to-tail selective hydroalkynylation alkynes (well established, ref. 5e-g)
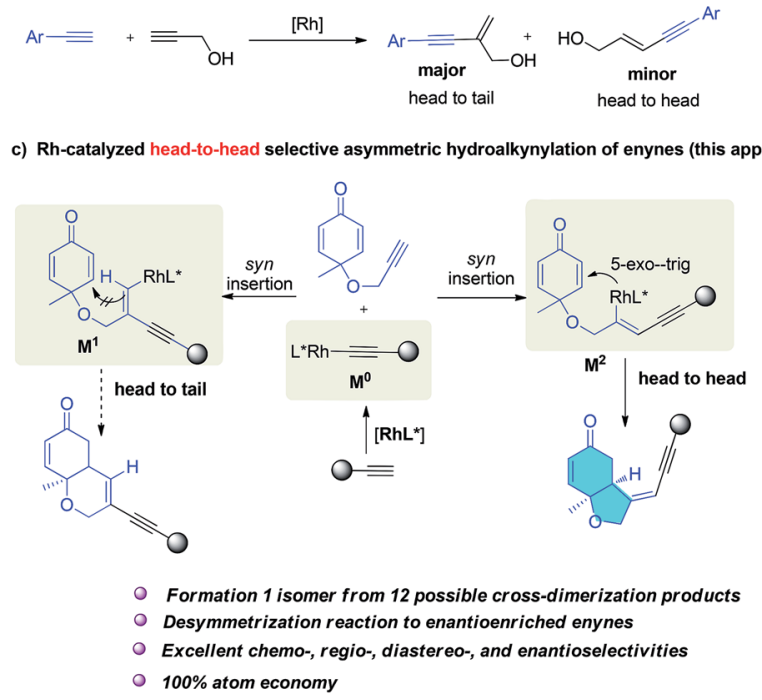

Scheme 1 Rh-catalyzed cross-hydroalkynylation of terminal alkynes. 
catalyst, ${ }^{5, j}$ but when rhodium catalyst was employed, head-totail dimers were obtained as a major product, together with some head-to-head isomers as byproducts (Scheme 1b). ${ }^{5 e-g}$ Herein, we report the first Rh-catalyzed asymmetric crosshydroalkynylation of 1,6-enynes via a selective head-to-head insertion and symmetry breaking Michael addition cascade. As illustrated in Scheme 1c, rhodium acetylide $\left(\mathbf{M}^{\mathbf{0}}\right)$ was selectively formed from a terminal alkyne and its subsequent syn addition to the alkyne moiety of enynes could generate two vinyl rhodium intermediates $\left(\mathbf{M}^{\mathbf{1}}, \mathbf{M}^{\mathbf{2}}\right) . \mathbf{M}^{\mathbf{2}}$ can undergo a fast 5-exo-trig cyclization to form the final bicyclic products. However, $\mathbf{M}^{\mathbf{1}}$ bearing a trans $\mathrm{C}-\mathrm{Rh}$ bond cannot undergo the Michael addition to form stabilized ring products. A possible $E / Z$ isomerization ${ }^{\mathbf{8}}$ of $\mathbf{M}^{\mathbf{1}}$ might generate a cis $\mathrm{C}-\mathrm{Rh}$ bond which could undergo Michael addition, but this will involve a much higher activation energy. Consequently, the formation of $\mathbf{M}^{2}$ would be preferred, delivering the head-to-head products selectively. More importantly, when a chiral phosphine ligand was applied, enantioenriched enynes bearing an important chiral cis-hydrobenzofuran moiety were obtained. This is a unique scaffold present in many bioactive natural products including incarviditone, ${ }^{9 a}$ isoambrox $^{9 \boldsymbol{b}}$ haterumaimide I, ${ }^{9 \boldsymbol{c}}$ and milling-tonine A. ${ }^{\boldsymbol{9} \boldsymbol{d}}$ To date, no examples of synthesis of chiral enynes by asymmetric crosshydroalkynylation process have been reported.

\section{Results and discussion}

A cyclohexadienone tethered terminal alkyne (1a) was selected as one partner in this reaction, because this prochiral electrondeficient diene is an excellent Michael acceptor with which to build chiral cis-hydrobenzofuranones by organo- or transitionmetal-catalyzed desymmetrization reactions. ${ }^{10,11}$ The aromatic alkyne (2a), bearing an alkyne proton which is more acidic than that in aliphatic alkynes, ${ }^{12}$ was chosen as the second partner to react with the enyne (1a) in the presence of a rhodium catalyst. The rhodium catalyst might react with 2 a to form phenylethynyl rhodium, and upon subsequent hydroalkynylation of 1a, deliver the cyclization products. To test this hypothesis, the reaction was performed in dichloroethane (DCE) at rt overnight in the presence of $5 \mathrm{~mol} \%$ of $[\mathrm{Rh}(\mathrm{COD}) \mathrm{Cl}]_{2}$ and $10 \mathrm{~mol} \%$ of $S$ BINAP. The desired head-to-head bicyclo[4.3.0] product (3a) was obtained in $72 \%$ isolated yield as a single diastereomer, and no head-to-tail bicyclo[4.4.0] product was observed in the reaction (Table 1, entry 1). These results are contrary to previous rhodium-catalyzed reactions which give head-to-tail structures as major products ${ }^{5 e-g}$ (Scheme $1 \mathrm{~b}$ ) and indicate the viability of the proposed reaction shown in Scheme 1c. In addition, HPLC analysis shows that the enantioselectivity of this reaction is as high as $94 \%$ ee.

Next, we sought to optimize the reaction conditions, obtaining the results shown in Table 1 . We first examined various diphosphine ligands (entries 1-6). Increasing the steric hindrance of the phosphine substituents led to lower enantioselectivities (entries 2 and 3). Biphenyl ligands such as SEGPHOS (L4) and MeO-BIPHEP (L5) gave almost quantitative yields but lower enantioselectivity (entries 4 and 5). When DIOP (L6) was employed, the highest $98 \%$ ee was obtained but with much lower
Table 1 Optimization of reaction conditions ${ }^{a}$

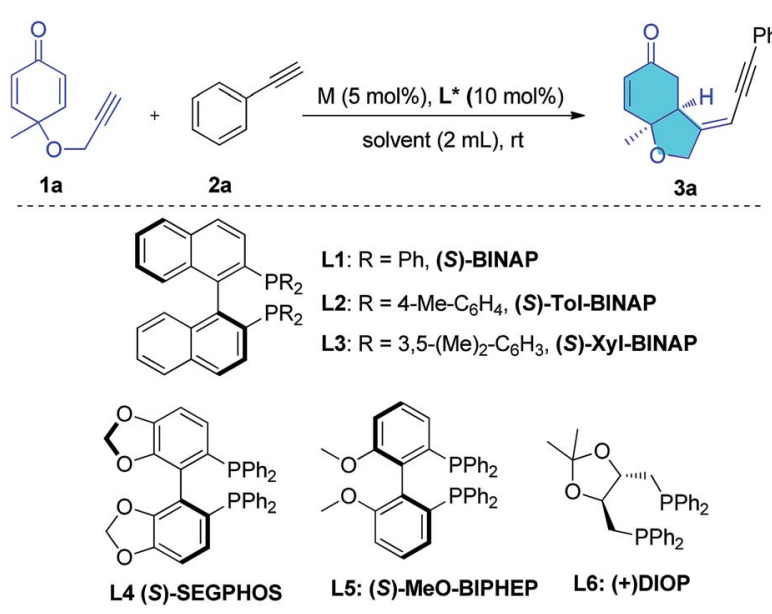

\begin{tabular}{|c|c|c|c|c|c|}
\hline Entry & Catalyst & Ligand & Solvent & Yield $^{b} / \%$ & $\mathrm{ee}^{c} / \%$ \\
\hline 1 & {$[\mathrm{Rh}(\operatorname{cod}) \mathrm{Cl}]_{2}$} & $\mathbf{L 1}$ & DCE & 72 & 94 \\
\hline 2 & {$[\mathrm{Rh}(\operatorname{cod}) \mathrm{Cl}]_{2}$} & $\mathbf{L} 2$ & DCE & 94 & 79 \\
\hline 3 & {$[\mathrm{Rh}(\operatorname{cod}) \mathrm{Cl}]_{2}$} & L3 & DCE & 50 & 83 \\
\hline 4 & {$[\mathrm{Rh}(\operatorname{cod}) \mathrm{Cl}]_{2}$} & L4 & DCE & 98 & 77 \\
\hline 5 & {$[\mathrm{Rh}(\operatorname{cod}) \mathrm{Cl}]_{2}$} & L5 & DCE & 99 & 88 \\
\hline 6 & {$[\mathrm{Rh}(\operatorname{cod}) \mathrm{Cl}]_{2}$} & L6 & DCE & 48 & 98 \\
\hline 7 & {$[\mathrm{Rh}(\operatorname{cod}) \mathrm{Cl}]_{2}$} & $\mathbf{L 1}$ & $\mathrm{MeOH}$ & 62 & 99 \\
\hline 8 & {$[\mathrm{Rh}(\operatorname{cod}) \mathrm{Cl}]_{2}$} & $\mathbf{L 1}$ & THF & 0 & - \\
\hline 9 & {$[\mathrm{Rh}(\operatorname{cod}) \mathrm{Cl}]_{2}$} & $\mathbf{L 1}$ & $\mathrm{DMF}$ & Trace & - \\
\hline 10 & {$[\mathrm{Rh}(\operatorname{cod}) \mathrm{Cl}]_{2}$} & $\mathbf{L 1}$ & Toluene & 59 & 92 \\
\hline 11 & {$[\mathrm{Rh}(\operatorname{cod}) \mathrm{Cl}]_{2}$} & $\mathbf{L 1}$ & $\mathrm{DCE}: \mathrm{MeOH}=3: 1$ & 81 & 98 \\
\hline 12 & {$[\mathrm{Rh}(\operatorname{cod}) \mathrm{Cl}]_{2}$} & L1 & DCE $: \mathrm{MeOH}=1: 1$ & 66 & 97 \\
\hline $13^{d}$ & {$[\mathrm{Rh}(\operatorname{cod}) \mathrm{Cl}]_{2}$} & L1 & DCE $: \mathrm{MeOH}=3: 1$ & 92 & 99 \\
\hline 14 & {$\left[\mathrm{Rh}\left(\mathrm{cp}^{*}\right) \mathrm{Cl}_{2}\right]_{2}$} & $\mathbf{L 1}$ & DCE & 0 & - \\
\hline 15 & $\mathrm{NiCl}_{2} \cdot 6 \mathrm{H}_{2} \mathrm{O}$ & $\mathbf{L 1}$ & DCE & 0 & - \\
\hline 16 & $\mathrm{Ni}(\mathrm{acac})_{2}$ & $\mathbf{L 1}$ & DCE & 0 & - \\
\hline
\end{tabular}

${ }^{a}$ Reaction conditions: $1 \mathrm{a}(0.1 \mathrm{mmol}), 2 \mathrm{a}(0.2 \mathrm{mmol})$, catalyst $(5 \mathrm{~mol} \%)$, and ligand $(10 \mathrm{~mol} \%)$, solvent $(2 \mathrm{~mL}), \mathrm{rt}^{b}$ Isolated yield. ${ }^{c}$ Determined by HPLC analysis on a chiral stationary phase. ${ }^{d} \mathbf{1 a}(0.2 \mathrm{mmol}), 2 \mathrm{a}(0.4$ $\mathrm{mmol}),[\mathrm{Rh}(\operatorname{cod}) \mathrm{Cl}]_{2}(2.5 \mathrm{~mol} \%)$, and $\mathbf{L 1}(5 \mathrm{~mol} \%)$.

yield (entry 6). The solvent effect was then investigated (entries 7-12). The reaction in $\mathrm{MeOH}$ was much more rapid, leading to $99 \%$ ee but lower isolated yield (62\%, entry 7$)$. We observed that when DCE was added to the $\mathrm{MeOH}$ solvent, a higher reaction yield was obtained without any obvious decrease in enantioselectivity (entries 11 and 12). Increasing the concentration of substrates and lowering the catalyst loading to $5 \mathrm{~mol} \%$ in the mixed solvent (DCE : $\mathrm{MeOH}=3: 1$ ) led to $92 \%$ isolated yield and $99 \%$ ee, and represents the optimal conditions (entry 13). When the Rh(I) catalyst was replaced by a Rh(III) catalyst (entry 14) or nickel catalysts (entries 15 and 16), no product was formed. Under the optimized conditions, this atom-economic reaction produces chiral hydrobenzofuranone-tethered enynes in high yield with extremely high enantioselectivity. Notably, the rhodium catalyst produced a single product from tens of possible products counting two new chiral centers by precise control of the chemo-, regio-, diastereo-, and enantioselectivities. Such reactions are very rare in organic synthesis. 
Having established the optimal conditions for this asymmetric enyne hydroalkynylation reaction, the scope of terminal alkynes was investigated. As shown in Table 2, various aromatic terminal alkynes reacted with enyne 1a under the optimized conditions, and the corresponding head-to-head hydroalkynylation products (3a-3q) were produced in good yields (50$97 \%$ ) and excellent enantioselectivity ( $92 \%$ to $>99 \%$ ee). Various electron-withdrawing or electron-donating functional groups at the para, ortho, or meta- positions do not affect this reaction (entries 1-11). Electron-donating groups generally favor the reaction and electron-withdrawing groups lead to slightly lower yields. Functional groups such as alkoxyl (3c), halogens (3d-3f), $\mathrm{CF}_{3}(\mathbf{3 c})$, and even an unprotected hydroxyl group $(\mathbf{3 i}, 3 \mathbf{j})$ are all tolerated. In the case of $2 \mathbf{j}$, the 2 -hydroxymethyl group led to decreased enantioselectivity ( $92 \%$ ee), but when the hydroxyl group was protected, $99 \%$ ee was obtained (entries 10 and 11). Terminal alkynes containing heterocycles, including indole and thiophene also reacted smoothly under the standard

Table 2 Substrate scope of alkene trifluoromethylthiosulfonylation reactions $^{a}$

\begin{tabular}{|c|c|c|c|c|c|}
\hline & 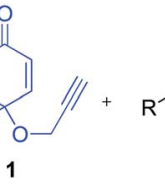 & $\begin{array}{l}{[\mathrm{Rh}(\mathrm{cod}) \mathrm{Cl}]_{2}(2.5 \mathrm{~mol}} \\
(\mathrm{S})-\mathrm{BINAP}(\mathrm{L} 1,5 \mathrm{~mol} \\
\text { DCE/MeOH }(3: 1), \mathrm{rt}\end{array}$ & & 3 & \\
\hline Entry & $\mathbf{1}\left(\mathrm{R}^{\prime}\right)$ & $2(\mathrm{R})$ & 3 & Yield $^{b} / \%$ & $\mathrm{ee}^{c} / \%$ \\
\hline 1 & 1a $(\mathrm{Me})$ & $2 \mathrm{a}\left(\mathrm{C}_{6} \mathrm{H}_{5}\right)$ & $3 a$ & 92 & 99 \\
\hline 2 & $1 \mathrm{a}$ & 2b $\left(4-\mathrm{MeC}_{6} \mathrm{H}_{4}\right)$ & $\mathbf{3 b}$ & 83 & 98 \\
\hline 3 & $1 \mathrm{a}$ & $2 c\left(4-\mathrm{MeOC}_{6} \mathrm{H}_{4}\right)$ & $3 c$ & 90 & 98 \\
\hline 4 & $1 \mathrm{a}$ & $2 d\left(4-\mathrm{FC}_{6} \mathrm{H}_{4}\right)$ & $3 d$ & 92 & $>99$ \\
\hline 5 & $1 \mathbf{a}$ & $2 \mathrm{e}\left(4-\mathrm{ClC}_{6} \mathrm{H}_{4}\right)$ & $3 e$ & 67 & $>99$ \\
\hline 6 & $1 \mathrm{a}$ & $2 f\left(4-\mathrm{BrC}_{6} \mathrm{H}_{4}\right)$ & $3 f$ & 66 & $>99$ \\
\hline 7 & $1 \mathrm{a}$ & $2 \mathrm{~g}\left(4-\mathrm{CF}_{3} \mathrm{C}_{6} \mathrm{H}_{4}\right)$ & $3 g$ & 73 & 99 \\
\hline 8 & $1 \mathrm{a}$ & 2 h $\left(3-\mathrm{MeC}_{6} \mathrm{H}_{4}\right)$ & $3 \mathbf{h}$ & 80 & 99 \\
\hline 9 & $1 \mathrm{a}$ & $2 \mathrm{i}\left(3-\mathrm{OHC}_{6} \mathrm{H}_{4}\right)$ & $3 \mathbf{i}$ & 64 & 99 \\
\hline 10 & $1 \mathrm{a}$ & $2 \mathbf{j}\left(2-\mathrm{CH}_{2} \mathrm{OHC}_{6} \mathrm{H}_{4}\right)$ & $3 \mathbf{j}$ & 50 & 92 \\
\hline 11 & $1 \mathrm{a}$ & $2 \mathbf{k}\left(2-\mathrm{CH}_{2} \mathrm{OTBSC}_{6} \mathrm{H}_{4}\right)$ & $3 \mathbf{k}$ & 58 & 99 \\
\hline 12 & $1 \mathrm{a}$ & $2 \mathbf{l}$ (1-naphthyl) & 31 & 81 & 99 \\
\hline 13 & $1 \mathrm{a}$ & 2m (2-naphthyl) & $3 m$ & 78 & 98 \\
\hline 14 & $1 \mathrm{a}$ & 2n (3-indolyl) & $3 n$ & 68 & 96 \\
\hline 15 & $1 \mathrm{a}$ & 20 (3-thienyl) & 30 & 96 & $>99$ \\
\hline 16 & $1 \mathrm{a}$ & $2 \mathbf{p}(2$-thienyl) & $3 \mathbf{p}$ & 97 & 99 \\
\hline 17 & $1 \mathrm{a}$ & $2 q($ ferrocenyl) & $3 q$ & 80 & $>99$ \\
\hline 18 & $1 \mathrm{a}$ & 2r (cyclopropyl) & $3 \mathbf{r}$ & 89 & $>99$ \\
\hline 19 & $1 \mathrm{a}$ & 2s $\left(\mathrm{C}_{6} \mathrm{H}_{5} \mathrm{CH}_{2} \mathrm{CH}_{2} \mathrm{CH}_{2}^{-}\right)$ & $3 s$ & 55 & $>99$ \\
\hline 20 & $1 \mathrm{a}$ & $2 \mathbf{t}\left(\mathrm{C}_{6} \mathrm{H}_{5} \mathrm{OCH}_{2}^{-}\right)$ & $3 t$ & 46 & 98 \\
\hline 21 & $1 \mathrm{a}$ & $2 u$ & $3 \mathbf{u}$ & 96 & $>99$ \\
\hline 22 & $1 \mathbf{b}(\mathrm{Et}-)$ & $2 \mathbf{a}\left(\mathrm{C}_{6} \mathrm{H}_{5}\right)$ & $3 \mathbf{v}$ & 93 & $>99$ \\
\hline 23 & $1 \mathbf{b}(\mathrm{Et}-)$ & $2 d\left(4-\mathrm{FC}_{6} \mathrm{H}_{4}\right)$ & $3 \mathbf{w}$ & 81 & $>99$ \\
\hline 24 & $1 c$ (i-propyl) & $2 a$ & $3 \mathbf{x}$ & 86 & 97 \\
\hline 25 & 1d $\left(\mathrm{C}_{6} \mathrm{H}_{5}\right)$ & $2 a$ & $3 y$ & 89 & 99 \\
\hline
\end{tabular}

${ }^{a}$ Reaction conditions: 1a $(0.2 \mathrm{mmol}), 2(0.4 \mathrm{mmol}),[\mathrm{Rh}(\operatorname{cod}) \mathrm{Cl}]_{2}$ (2.5 $\mathrm{mol} \%$ ), and L1 (5 mol\%), rt. ${ }^{b}$ Isolated yield. ${ }^{c}$ Determined by HPLC analysis on a chiral stationary phase. conditions, delivering corresponding enantioenriched enynes in good yields and with 96-99\% ee (entries 14-16). Remarkably, the ferrocene-derived alkyne (2q) was also suitable for this reaction and gave the cyclization product (3q) in $80 \%$ yield and with over $99 \%$ ee (entry 17 ). Two single crystals of products $\mathbf{3 m}$ and $3 \mathbf{p}$ were grown to confirm their structures and stereochemistry. The absolute configuration of these two products were established as $S$ and $S$ by X-ray crystallography (Scheme 2).

Selective cross-dimerization of two aliphatic alkynes is more challenging and is unprecedented. The cyclopropyl alkyne (2r) and cyclohexenyl alkyne (2u) react equally well under these conditions and give the corresponding bicyclic products $(3 \mathbf{r}, \mathbf{3 u})$ in excellent yields ( $89 \%$ and $96 \%)$ and enantioselectivity $(>99 \%$ ee), (entries 18 and 21). Simple linear aliphatic alkynes (2s, 2t) were converted to the corresponding bicyclic enynes in acceptable yields with excellent enantioselectivities ( $99 \%$ and $98 \%$ ee), (entries 19 and 20). The scope of the enynes was also studied. Enynes containing aliphatic groups such as ethyl or the bulkier isopropyl, and a phenyl group at the prochiral quaternary carbon center all reacted smoothly to give the corresponding desymmetrization products in excellent yields and enantioselectivities (entries 22-25). The nitrogen bridged enyne (1e) was also amenable to this transformation, giving the nitrogen heterocycle (4) in $94 \%$ yield and $98 \%$ ee (eqn (1)).

In a large scale reaction, $1.14 \mathrm{~g}$ of $3 \mathrm{a}$ was isolated in $86 \%$ yield and $99 \%$ ee with low catalyst loading, demonstrating the remarkable practicality of this method (eqn (2)). Further synthetic transformations of the bicyclic enynes were explored (Scheme 3). Selective reduction of the ketone group by $\mathrm{NaBH}_{4}$ afforded an allyl alcohol (5) in 93\% yield with $98 \%$ ee. Pd/Ccatalyzed hydrogenation of 3a with a balloon of $\mathrm{H}_{2}$ led to complete hydrogenation of the enyne moiety in the side chain and enone affording ketone (6) in $95 \%$ yield. Conjugated borylation of $3 \mathrm{a}$ with $\mathrm{B}_{2} \mathrm{Pin}_{2}$ in the presence of CuI gave the borate (7) in $72 \%$ yield and $99 \%$ ee. The silyl enol ether (8) was prepared to undergo a gold-catalyzed intramolecular Conia-ene reaction, the addition of enol ether to alkyne moiety to yield cyclized products, but the desired tricyclic product was not formed, and instead, a phenol tethered enyne (9) was produced in $85 \%$ yield through an aromatized $\mathrm{C}-\mathrm{O}$ bond cleavage. It should be noted that formally, this is a meta-functionalization reaction of phenol, which is very difficult to achieve by known methods.

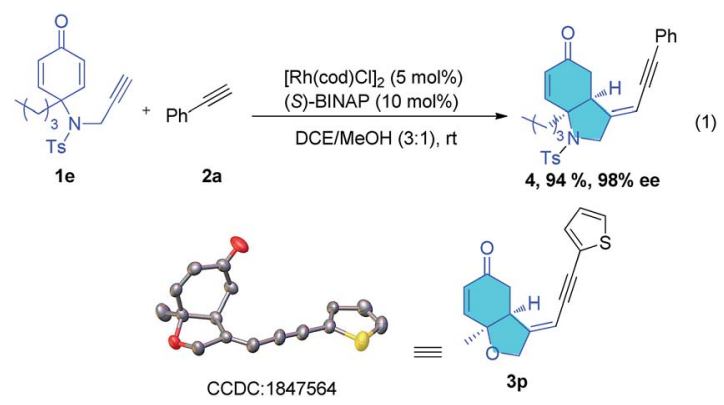

Scheme 2 X-ray crystallographic structure of $3 p$. 


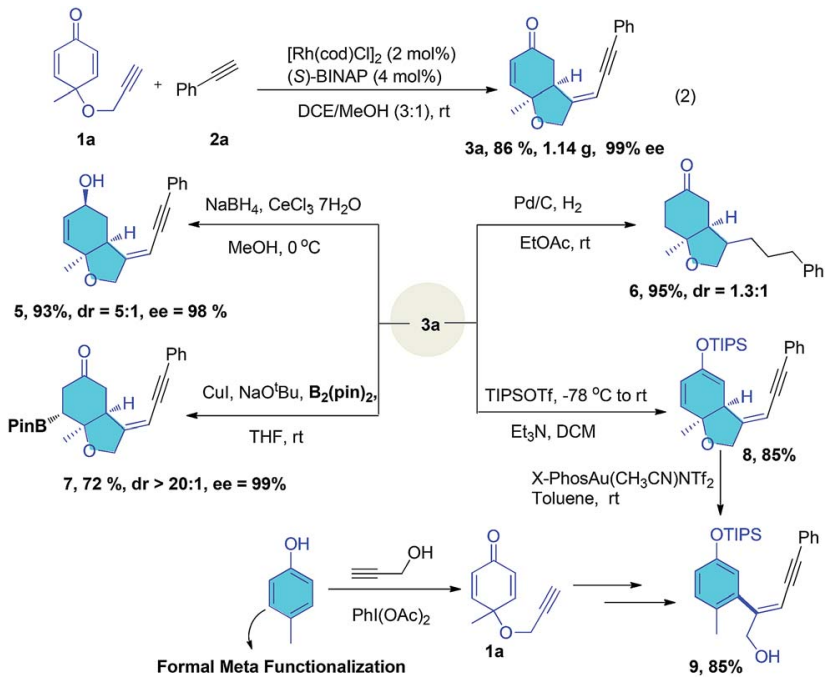

Scheme 3 Scale-up experiment and further synthetic applications of bicyclic enynes.

To gain insight into the hydroalkynylation process, we conducted deuterium labelling experiments (Scheme 4). The standard reaction in MeOD led to 3a-D with 50\% deuterium content at the methylene position adjacent to the ketone (eqn (3)).

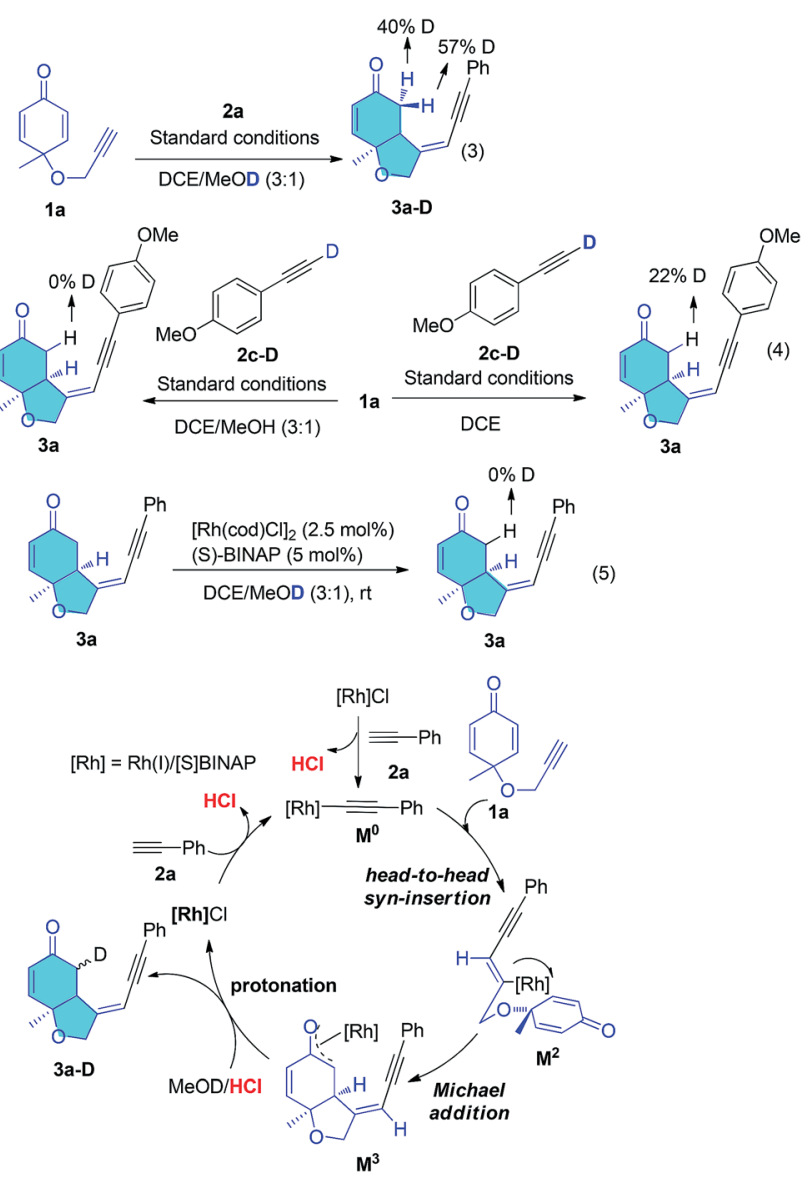

Scheme 4 Control experiments and proposed mechanism.
When the deuterated alkyne 2c-D was subjected to the reaction in $\mathrm{MeOH}$, the $\mathrm{CH}_{2}$ was not deuterated at all, but when the reaction was performed in DCE solution, the proton was $22 \%$ deuterated (eqn (4)). Product 3a was not deuterated under standard conditions in MeOD (eqn (5)). These results indicate that the origin of this hydrogen could be the alkyne proton and solvent. Based on these results and previous reports, a plausible mechanism is proposed and shown in Scheme 4 . Rh(I) catalyst reacted with 2 a forming $\mathrm{Rh}(\mathrm{I})$ acetylide $\mathbf{M}^{\mathbf{0}}$ and released catalytic amount of $\mathrm{HCl}$, which might exchange with solvent methanol and played a very important role in the final protonation step. $\mathrm{Rh}(\mathrm{I})$ acetylide $\mathbf{M}^{\mathbf{0}}$ went through head-to-head insertion afforded the vinyl rhodium intermediate $\left(\mathbf{M}^{2}\right)$. Asymmetric Michael addition to this prochiral diene gave an $\mathrm{Rh}(\mathrm{I})$ enolate $\left(\mathbf{M}^{\mathbf{3}}\right)$, which was protonated by $\mathrm{HCl} / \mathrm{MeOH}$ to form the product (3a) and $\mathrm{Rh}(\mathrm{I}) \mathrm{Cl}$. This final unselective protonation of $\mathrm{Rh}(\mathrm{I})$ enolate $\left(\mathbf{M}^{3}\right)$ with $\mathrm{HCl} / \mathrm{MeOD}$ could result in both protons of the methylene group being deuterated, which would be consistent with eqn (3). If the first formation of $\mathrm{Rh}(\mathrm{I})$ acetylide $\mathbf{M}^{\mathbf{0}}$ was oxidative addition, then the final step should be reductive elimination and the proton of the methylene group should come from the terminal alkyne, which fails to agree with eqn (3). If $[\mathrm{Rh}(\mathrm{COD}) \mathrm{OMe}]_{2}$ catalyst was used instead of chloride catalyst, much slower reaction and lower yield was observed, because this catalyst reacted with terminal alkyne only produce neutral methanol, but not acid.

\section{Conclusions}

In summary, we have developed a highly enantioselective Rhcatalyzed hydroalkynylation reaction that can be used for the synthesis of enantioenriched cis-hydrobenzofuranone-tethered enynes. Although many isomers are possible, a single head-tohead regioisomer was obtained in this reaction. Notable features of this approach include 100\% atom-economy, mild reaction conditions, a very broad substrate scope, and precise control of chemo-, regio-, diastereo- and enantioselectivity by a single catalyst. Further application of this strategy is in progress in our laboratory.

\section{Conflicts of interest}

There are no conflicts to declare.

\section{Acknowledgements}

We are grateful for financial support from the Natural Science Foundation of China (no. 21572118), and Tang scholar award and The Fundamental Research Funds of Shandong University. We thank Prof. Dr Di Sun who carried out the X-ray crystallographic analysis.

\section{Notes and references}

1 (a) P. Lan, L. E. White, E. S. Taher, P. E. Guest, M. G. Banwell and A. C. Willis, J. Nat. Prod., 2015, 78, 1963; (b) 
P. Nussbaumer, I. Leitner, K. Mraz and A. Stütz, J. Med. Chem., 1995, 38, 1831.

2 Y. Liu, M. Nishiura, Y. Wang and Z. Hou, J. Am. Chem. Soc., 2006, 128, 5592.

3 (a) P. McGee, G. Bétournay, F. Barabé and L. Barriault, Angew. Chem., Int. Ed., 2017, 56, 6280; (b) J. Cheng and T.-P. Loh, J. Am. Chem. Soc., 2015, 137, 42; (c) Y. Wang, P. Zhang, D. Qian and J. Zhang, Angew. Chem., Int. Ed., 2015, 54, 14849; (d) W. Zhang, S. Zheng, N. Liu, J. B. Werness, I. A. Guzei and W. Tang, J. Am. Chem. Soc., 2010, 132, 3664.

4 (a) B. M. Trost, M. T. Sorum, C. Chan, A. E. Harms and G. Rühter, J. Am. Chem. Soc., 1997, 119, 698; (b) B. M. Trost, B. R. Taft, J. T. Masters and J.-P. Lumb, J. Am. Chem. Soc., 2011, 133, 8502.

5 For a review, see: $(a)$ B. M. Trost and J. T. maters, Chem. Soc. Rev., 2016, 45, 2212; For recent examples, see:(b) Q. Liang, K. M. Osten and D. Song, Angew. Chem., Int. Ed., 2017, 56, 6317; (c) M. G. Lauer, B. R. Headford, O. M. Gobble, M. B. Weyhaupt, D. L. Gerlach, M. Zeller and K. H. Shaughnessy, ACS Catal., 2016, 6, 5834; (d) O. RivadaWheelaghan, S. Chakraborty, L. J. W. Shimon, Y. Ben-David and D. Milstein, Angew. Chem., Int. Ed., 2016, 55, 6942; (e) R. Azpíroz, L. Rubio-Pérez, R. Castarlenas, J. J. PérezTorrente and L. A. Oro, ChemCatChem, 2014, 6, 2587; $(f)$ H.-D. Xu, R. Zhang, X. Li, S. Huang, W. Tang and W.-H. Hu, Org. Lett., 2013, 15, 840; (g) H. M. Peng, J. Zhao and X. Li, Adv. Synth. Catal., 2009, 351, 1371; (h) R. H. Platel and L. L. Schafer, Chem. Commun., 2012, 48, 10609; (i) C.-C. Lee, Y.-C. Lin, Y.-H. Liu and Y. Wang, Organometallics, 2005, 24, 136; (j) C. Jahier, O. V. Zatolochnaya, N. V. Zvyagintsev, V. P. Ananikov and V. Gevorgyan, Org. Lett., 2012, 14, 2846; (k) C.-H. Jun, Z. Lu and R. H. Crabtree, Tetrahedron Lett., 1992, 33, 7119.

6 Rh-catalyzed asymmetric hydroalkynylation of alkene moiety has been well developed, see: (a) X.-Y. Bai, W.-W. Zhang, Q. Li and B.-J. Li, J. Am. Chem. Soc., 2018, 140, 506; (b) K.-L. Choo and M. Lautens, Org. Lett., 2018, 20, 1380; (c) Y. Zhi, J. Huang, N. Liu, T. Lu and X. Dou, Org. Lett., 2017, 19, 2378; (d) X.-Y. Bai, Z.-X. Wang and B.-J. Li, Angew. Chem., Int. Ed., 2016, 55, 9007; (e) X. Dou, Y. Huang and T. Hayashi, Angew. Chem., Int. Ed., 2016, 55, 1133; $(f)$ Q. Yang, P. Y. Choy, B. Fan and F. Y. Kwong, Adv. Synth. Catal., 2015, 357, 2345; (g) B.-M. Fan, Q.-J. Yang, J. Hu, C.-L. Fan, S.-F. Li, L. Yu, C. Huang, W. W. Tsang and F. Y. Kwong, Angew. Chem., Int. Ed., 2012, 51, 7821; (h) T. Nishimura, T. Sawano and T. Hayashi, Angew. Chem., Int. Ed., 2009, 48, 8057; (i) T. Nishimura, X.-X. Guo, N. Uchiyama, T. Katoh and T. Hayashi, J. Am. Chem. Soc.,
2008, 130, 1576; (j) D. F. Cauble, J. D. Gipson and M. J. Krische, J. Am. Chem. Soc., 2003, 125, 1110.

7 Z. Yan, X.-A. Yuan, Y. Zhao, C. Zhu and J. Xie, Angew. Chem., Int. Ed., 2018, 57, 12906.

8 C. Clarke, C. A. Incerti-Pradillos and H. W. Lam, J. Am. Chem. Soc., 2016, 138, 8068.

9 (a) Y.-Q. Chen, Y.-H. Shen, Y.-Q. Su, L.-Y. Kong and W.-D. Zhang, Chem. Biodiversity, 2009, 6, 779; (b) K. Zhao, G.-J. Cheng, H. Yang, H. Shang, X. Zhang, Y.-D. Wu and Y. Tang, Org. Lett., 2012, 14, 4878; (c) J. M. Castro, S. Salido, J. Altarejos, M. Nogueras and A. Sánchez, Tetrahedron, 2002, 58, 5941; (d) M. J. Uddin, S. Kokubo, K. Ueda, K. Suenaga and D. Uemura, J. Nat. Prod., 2001, 64, 1169; (e) T. Hase, K. Ohtani, R. Kasai, K. Yamasaki and C. Picheansoonthon, Phytochemistry, 1996, 41, 317.

10 For a review on desymmetrization reactions: (a) X.-P. Zeng, Z.-Y. Cao, Y.-H. Wang, F. Zhou and J. Zhou, Chem. Rev., 2016, 116, 7330; For organo-catalyzed desymmetrization of cyclohexadienone, see:(b) X. Su, W. Zhu, Y. Li and J. Zhang, Angew. Chem., Int. Ed., 2015, 54, 6874; (c) S. Takizawa, T. M.-N. Nguyen, A. Grossmann, D. Enders and H. Sasai, Angew. Chem., Int. Ed., 2012, 51, 5423; (d) Q. Gu and S.-L. You, Chem. Sci., 2011, 2, 1519; (e) Q. Gu, Z.-Q. Rong, C. Zheng and S.-L. You, J. Am. Chem. Soc., 2010, 132, 4056; $(f)$ N. T. Vo, R. D. M. Pace, F. O'Hara and M. J. Gaunt, J. Am. Chem. Soc., 2008, 130, 404; $(g)$ Q. Liu and T. Rovis, J. Am. Chem. Soc., 2006, 128, 2552; (h) W. Yao, X. Dou, S. Wen, J. Wu, J. J. Vittal and Y. Lu, Nat. Commun., 2016, 7, 13024.

11 For metal-catalyzed desymmetrization of cyclohexadienone, see: (a) T. Shu, L. Zhao, S. Li, X.-Y. Chen, C. von Essen, K. Rissanen and D. Enders, Angew. Chem., Int. Ed., 2018, 57, 10985; (b) X. Zhou, Y. Pan and X. Li, Angew. Chem., Int. Ed., 2017, 56, 8163; (c) J. Chen, X. Han and X. Lu, Angew. Chem., Int. Ed., 2017, 56, 14698; (d) R. Kumar, Y. Hoshimoto, E. Tamai, M. Ohashi and S. Ogoshi, Nat. Commun., 2017, 8, 32; (e) Z.-T. He, X.-Q. Tang, L.-B. Xie, M. Cheng, P. Tian and G.-Q. Lin, Angew. Chem., Int. Ed., 2015, 54, 14815; (f) P. Liu, Y. Fukui, P. Tian, Z.-T. He, C.-Y. Sun, N.-Y. Wu and G.-Q. Lin, J. Am. Chem. Soc., 2013, 135, 11700; $(g)$ Z.-T. He, B. Tian, Y. Fukui, X. Tong, P. Tian and G.-Q. Lin, Angew. Chem., Int. Ed., 2013, 52, 5314; $(h)$ J. Keilitz, S. G. Newman and M. Lautens, Org. Lett., 2013, 15, 1148; (i) T. L. N. Nguyen, C. A. Incerti-Pradillos, W. Lewis and H. W. Lam, Chem. Commun., 2018, 54, 5622; (j) K. K. Gollapelli, S. Donikela, N. Manjula and R. Chegondi, ACS Catal., 2018, 8, 1440.

12 A. J. Kresge and P. Pruszynski, J. Org. Chem., 1991, 56, 4808. 